\title{
MOTIVAÇÃO E LIDERANÇA COMO ESTRATÉGIAS NA GESTÃO DE PESSOAS: O TRABALHO DO GESTOR NUMA ESCOLA PARTICULAR DO MUNICÍPIO DE SÃO JERÔNIMO/RS
}

\author{
MOTIVATION AND LEADERSHIP AS STRATEGIES IN PEOPLE \\ MANAGEMENT: THE MANAGER'S WORK AT A PRIVATE SCHOOL IN THE \\ MUNICIPALITY OF SÃO JERÔNIMO / RS
}

Fabio Rafael Corrêa de Oliveira ${ }^{1}$

Bruno da Silva Nascimento Soares ${ }^{2}$

Gislaine Silveira Nunes ${ }^{3}$

Aline Andressa Trennepohl Borges ${ }^{4}$

Suelen da Rosa Teixeira ${ }^{5}$

Leandro Luis de Lima ${ }^{6}$

RESUMO: O trabalho apresentado tem como questionamento central o modo como uma gestora escolar analisa seu trabalho frente a um grupo de professores de uma escola particular, motivando, liderando e resolvendo problemas burocráticos, administrativos e pedagógicos tudo ao mesmo tempo. Este trabalho tem como objetivo analisar quais fatores da organização que mais influenciam o grupo de professores de uma escola particular do município de São Jerônimo pela visão da gestora escolar, sua busca para motivar o grupo de professores e funcionários e como exerce sua liderança perante os colaboradores. As metodologias utilizadas foram a pesquisa bibliográfica e a pesquisa de campo, onde foi montado um estudo de caso pautado em entrevista de cinco perguntas abertas feitas para a gestora da escola de Educação Infantil e um levantamento bibliográfico sobre motivação e liderança. Seus resultados mostram que dentro dos fatores que mais motivam os funcionários são o reconhecimento aos

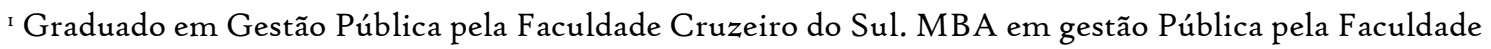
Cruzeiro do Sul. Policial Penal SEAPEN/RS. E-mail: rafael.oliveira.msn@hotmail.com.

${ }^{2}$ Graduado em Administração pelo Centro Universitário Metodista (IPA). Pós-graduado em Gestão Prisional pela Faveni. Policial Penal da SEAPEN/RS. E-mail: Bruno.nascimento.adm@gmail.com.

3 Graduada em Comunicação Social- Habilitada em Relações Públicas pela Universidade Federal do Rio Grande do Sul (UFRGS). Pós-graduada em Perfis criminais e comportamentais pela IBRA. Policial Penal da SEAPEN/RS. E-mail:gislainesilveirar6@gmail.com.

4 Graduada em Ciências Contábeis pela Universidade de Passo Fundo (UPF). Pós-graduada em Segurança Pública pela Faculdade Alfamérica. Policial Penal da SEAPEN/RS. E-mail: aline_atb@hotmail.com.

5 Graduada em Gestão Ambiental pela Universidade da Região da Campanha(URCAMP). Pósgraduada em Perícia e Auditoria Ambiental pela Uninter. Pós-graduada em Segurança Pública e Cidadania pela IBRA. Policial Penal da SEAPEN/RS.E-mail:suelen.teixeira@hotmail.com.

${ }^{6}$ Graduado em Segurança Pública pela Universidade Luterana do Brasil (ULBRA). Especialista em Direito Criminal pela Uniasselvi. Policial Penal SEAPEN/RS. E-mail: leandro-luis@susepe.rs.gov.br.
} 
trabalhos feitos e a possibilidade de opinar sobre as melhorias a serem realizadas na escola e os que menos motivam são os fatores salariais e a comunicação.

Palavras-chave: Motivação. Liderança. Gestor Escolar. Teorias Motivacionais. Formas de liderança.

ABSTRACT: The present article has a central question the way how school manager evoluates her work tow ards a group of teachers of a private school, motivating, leading and solving bureaucrati, administrative and pedagogical all at the same time. This article aims to evaluate the organization's group factores that influenced most the teacher's group of a private kindergarten school from São Jerônimo city by the vision of the school manager, her intent to motivate teacher's and school staff and how she exercise har leader ship withen the organization. It is presented as a case study based on a survey corpored of five open questions appliedto the manager of the kindergarten school and a bibliographic survey about motivation and leadership. The methodologies utilized were bibliography and field research, with which was composed a case study based on a survey. The outcome shows that among the factores that most motivate the employees are the recognition for the work done and the possibility to give opinion about the improviments to be done at the school. The onis that less motivate them are salary and communication.

Keywords: Motivation. Leadership. School manager. Motivational theories. Leadership types.

\section{INTRODUÇÃO}

Realizar o trabalho de gestor escolar nos dias de hoje é saber motivar, liderar, coordenar e administrar uma escola de maneira a contemplar companheiros de equipe, pais e comunidade em geral. Este trabalho apresenta a proposta de analisar sobre a óptica da gestora quais fatores da organização empresarial mais influenciam o grupo no processo de motivação para efetuar um trabalho de qualidade na escola de Educação Infantil localizada em São Jerônimo/RS, assim como o tipo de liderança que ela exerce sobre a equipe perante as respostas obtidas pelos questionamentos feitos. Para realizar a análise é necessário compreender o que é gestão escolar e o que se faz na mesma, assim como conhecer o significado de motivação e liderança.

O estudo se faz pertinente, pois hoje a educação perante a sociedade é um produto e sendo assim deve ser entregue da melhor forma possível e com a melhor excelência do mercado. Manter os profissionais da escola motivados para que a qualidade se mantenha sempre estável é algo difícil visto que se trabalha com pessoas e todas apresentam fatores motivacionais diferentes umas das outras. O mesmo se 
pode falar em questão de liderança, o modo como a equipe reage diz muito sobre como o gestor influencia no ambiente de serviço.

A ideia sobre este trabalho surgiu da dificuldade de manter o nível de uma equipe escolar motivada, pois muitas vezes há discordâncias e desentendimentos sobre ideias e se o gestor não souber coordenar corre-se o perigo da lassidão e da falta de comprometimento com a empresa, aqui no caso a escola particular de Educação Infantil e também do modo como o gestor analisa seu processo de liderança, como ele descreve sua atitude perante toda a equipe.

A bibliografia utilizada para dar o suporte teórico necessário à questão a ser respondida baseia-se em livros teóricos da administração de empresas que tratam de assuntos como a motivação e a gestão de pessoas, trazendo para este trabalho teóricos respeitados como Chiavenato (1994, 2009 e 2014), Robbins (2014), Fachada (2003), Bergamini (2008), Paro (2008), Gil (2011), Luck (2010) entre outros.

Portanto, a meta deste trabalho foi responder a seguinte pergunta: Como o gestor escolar exerce sua liderança e motiva sua equipe de trabalho numa escola de Educação infantil lidando com tantas tarefas administrativas, pedagógicas e burocráticas ao mesmo tempo?

\section{I A IMPORTÂNCIA DA GESTÃO ESCOLAR}

O gestor escolar é a pessoa responsável por interligar a escola com a sociedade, é ela quem busca criar projetos para resolver os problemas que circundam o meio escolar durante o ano letivo da escola. è acima de tudo um ato político, administrativo e de liderança, pois trabalha com todos os setores da sociedade e tem por objetivo uma educação de qualidade.

A tarefa de um gestor está baseada na política, construída com princípios de valorização do magistério, de gestão democrática, de qualidade, liberdade e de igualdade de opiniões.

Para um tratamento objetivo da atividade administrativa escolar é preciso, portanto, que a análise dos elementos mais especificamente relacionados à administração e à escola seja feita em íntima relação com o exame da 
maneira como está a sociedade organizada e das forças econômicas, políticas e sociais aí presentes (PARO,2008, p.13).

A gestão escolar não é algo simples, envolve a observação, a administração, a docência e a observação e cuidado em todas as esferas do âmbito escolar, fazendo da gestão uma eterna política entre os envolvidos, sempre arquitetando um crescimento escolar e um crescimento profissional e pessoal de cada um dos seus colaboradores.

Para Valerien (1993) o diretor tem sido cada vez mais obrigado a trabalhar com a ideia de democracia, de tomada de decisões conjuntas com a equipe, levando em consideração a opinião e ideias dos colegas. Luck (2010) complementa que quando os professores participam da gestão analisando e discutindo os problemas as soluções aparecem se tornam um processo de realização coletiva, onde todos reconhecem seus direitos e deveres.

Trabalhar como gestor importa em favorecer o trabalho do coletivo, de forma estratégica a promover a satisfação dos funcionários, estimulando a capacidade de todos e o envolvimento nas mais diversas tarefas, fortalecendo assim a instituição e interferindo diretamente na qualidade e eficácia educacional.

\subsection{O QUE É MOTIVAÇÃO?}

Para Gil (20II) a motivação é o combustível responsável para que a empresa possa trabalhar, gerando lucros e desenvolvimento para si. Já Bergamini (2008) acredita que as empresas devem captar a criatividade individual de cada colaborador e usar o seu potencial para trazer novas ideias para a organização.

As pessoas motivadas ficam mais dispostas a realizar seu trabalho, ficam a vontade, enquanto as insatisfeitas ficam cada vez mais desmotivadas, conclui Robbins (2009), complementando estas definições acima, temos Minicucci (2003) dizendo: a motivação faz com que o indivíduo alcance seu objetivo e metas traçadas tornando-se uma força que faz realizar a ação.

Definimos a motivação como os processos que representam a intensidade, a direção e a persistência de um indivíduo para alcançar uma meta. [...] A intensidade descreve o quanto uma pessoa se esforça. Este é o elemento no qual a maioria de nós se concentra quando falamos sobre motivação. No entanto, é pouco provável que a alta intensidade leva a resultados favoráveis de desempenho de trabalho, a menos que o esforço seja canalizado em uma direção que beneficie a organização. Por isso, consideramos a qualidade do 
esforço bem como sua intensidade. O esforço direcionado às metas da organização, e consistente com elas, é o tipo de esforço que deve ser procurado. Por fim, a motivação tem uma dimensão de persistência. A persistência mede por quanto tempo uma pessoa consegue manter o esforço. Quando motivados, os indivíduos conseguem manter uma tarefa por tempo suficiente até alcançar sua meta. (ROBBINS, 2014, p. 133-134)

Chiavenato (2009) define a motivação como tudo aquilo que impulsiona o ser humano a agir de uma maneira determinada, buscando um comportamento específico. O impulso pode ser um estímulo interno - processos mentais - ou externos, quando vindos do ambiente.

Motivação move as pessoas por diversas formas e para alcançar diversos objetivos, uma pessoa motivada traz maiores benefícios a si e a empresa, as tarefas são desempenhadas com prazer e há retorno para todos. As motivações podem variar de um momento para o outro, assim como de pessoa para pessoa, basta entendermos o momento, a situação.

\subsection{TEORIAS DA MOTIVAÇÃO}

Este trabalho vai abranger as três primeiras teorias da motivação que foram

criadas na década de 5o, hoje elas ainda estão em uso, porém serviram de base para as teorias contemporâneas existentes, após o questionário buscaremos achar características delas nas respostas obtidas.

\subsection{TEORIA DE MASLOW OU DA HIERARQUIA DAS NECESSIDADES}

Para Robbins (2014), Maslow criou a teoria motivacional mais conhecida até hoje, onde nela o homem possui uma hierarquia de cinco necessidades:

I. Fisiológicas: a fome, a sede, o frio, o sexo, as necessidades do corpo.

2. Segurança: proteção contra danos físicos e emocionais.

3. Sociais: Afeto, aceitação, amizade.

4. Estima: aqui temos como fatores internos a autoestima, autonomia, realização; como fatores externos citamos: o status, o reconhecimento social e a atenção.

5. Autorrealização: crescimento profissional, potencial alcançado, autorrealização. 
Segundo o autor, nenhuma necessidade fica plenamente satisfeita, porém quando uma está substancialmente satisfeita deixa de ser motivadora e o homem vai em busca da próxima necessidade, subindo assim na escala da pirâmide de Maslow. Robbins (2014) ainda esclarece que Maslow ao criar esta pirâmide definiu as necessidades em cinco partes, as três primeiras de baixo para cima são as fisiológicas e a de segurança, são satisfeitas externamente, a parte superior da pirâmide apresenta as realizadas internamente, tendo a autoestima e a autorrealização no topo.

Figura I- Pirâmide das Necessidades de MAslow

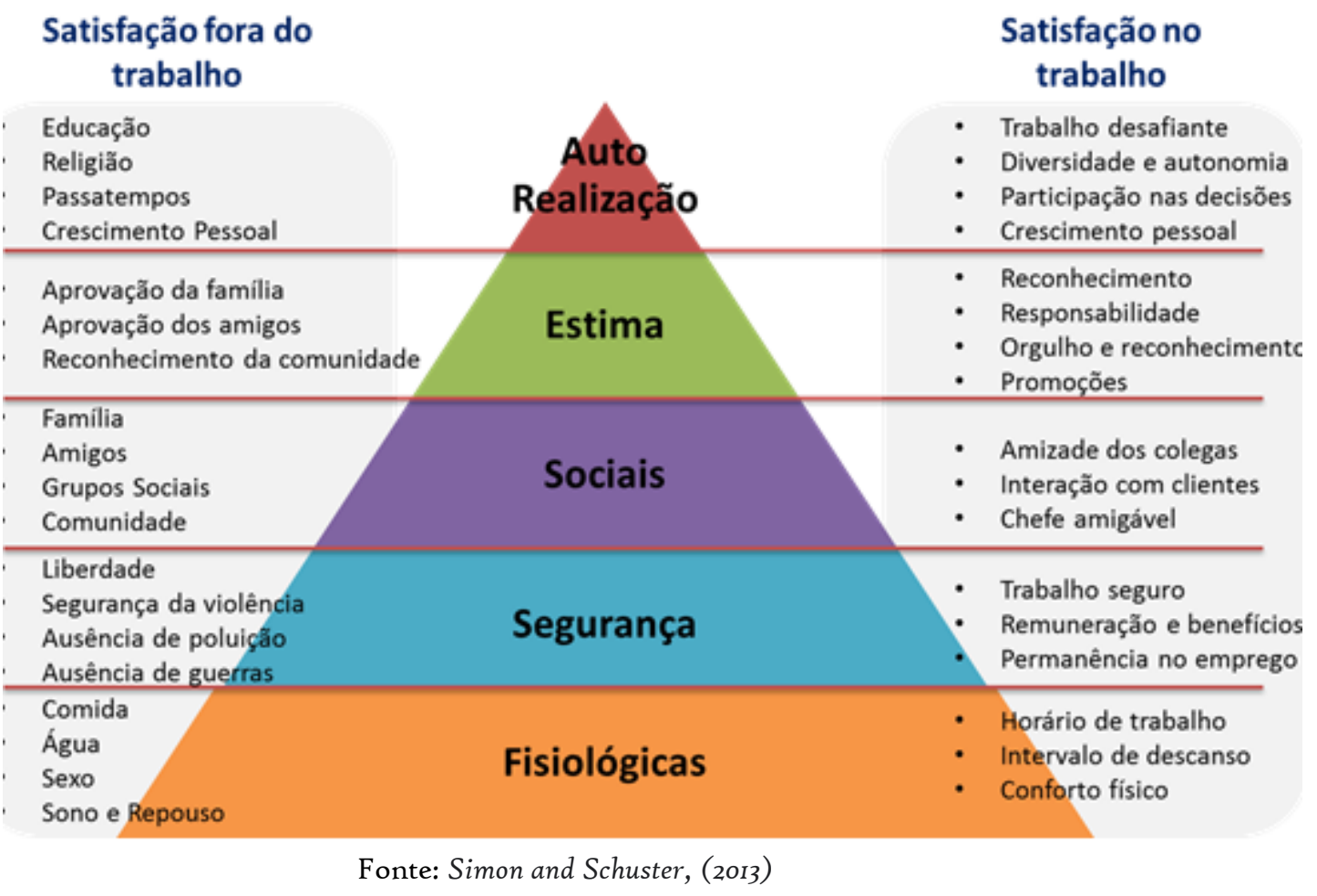

\subsubsection{A TEORIA X E A TEORIA Y}

Douglas McGregor propôs duas visões distintas do ser humano: uma basicamente negativa, chamada de Teoria X; outra basicamente positiva, chamada de Teoria Y. Depois de observar a forma como os executivos tratavam seus funcionários, McGregor concluiu que a visão que os executivos têm da natureza dos seres humanos se baseia em certos agrupamentos de premissas e que eles tendem a moldar seu próprio comportamento em relação aos funcionários conforme este conjunto de premissas. (ROBBINS, 2014, p.136)

Para Douglas McGregor, ainda segundo Robbins (2014), os gestores basearam-se em duas posições antagônicas sobre o comportamento de seus 
funcionários, um dos comportamentos foi chamado de Teoria $\mathrm{X}$, lado negativo e o Teoria Y, lado positivo.

No lado positivo temos o funcionário que está motivado, satisfeito e em busca de novas responsabilidades, no lado oposto temos o funcionário que precisa ser comandado, não tem iniciativa, desmotivado, fugindo de novas tarefas e responsabilidades. Robbins explica que ao comparar as duas teorias - a de Maslow e a de McGregor - o topo da pirâmide dominaria o indivíduo, portanto trabalhos responsáveis e desafios, assim como a participação coletiva e as boas relações de trabalho são fatores de motivação a serem propiciados na empresa para que os funcionários apresentem uma motivação mais persistente.

\subsubsection{TEORIA DOS DOIS FATORES}

Frederick Herzberg acreditou que a relação intrínseca entre o homem e o trabalho é fator primordial de motivação. A Teoria dos Dois Fatores também é chamada de Teoria da Motivação e Higiene. Robbins explica:

[...] fatores intrínsecos, como o avanço, o reconhecimento, a responsabilidade e a realização, parecem estar relacionados com a satisfação no trabalho. Os entrevistados que se sentiam bem com seu trabalho tendiam a atribuir esses fatores a eles mesmos, enquanto os que estavam insatisfeitos tendiam a citar fatores extrínsecos, como a supervisão, a remuneração, a política da empresa e as condições de trabalho. Para Herzberg, [...] o oposto da "satisfação" é "nenhuma satisfação" e o oposto de "insatisfação" é "nenhuma insatisfação".

De acordo com Herzberg, os fatores que levam à satisfação são separados e distintos daqueles que levam à insatisfação no trabalho. Portanto, os gestores que buscam eliminar fatores que possam criar insatisfação no trabalho podem fazer com que aja paz, mas não necessariamente motivação. Estão apaziguando em vez de motivar seus funcionários. [...] Herzberg sugeriu fatores associados com o trabalho em si ou com resultados diretamente dele derivados, como oportunidades de promoção, oportunidades de crescimento pessoal, reconhecimento, responsabilidade e realização. (ROBBINS, 2014, p. 137-138)

Os fatores motivacionais segundo Chiavenato (2009, p. 129) são:

- Delegação de responsabilidade;

-Liberdade de exercer discrição;

-Promoção e oportunidade de futuro;

-Uso pleno das habilidades e competências pessoais;

- Simplificação do cargo (pelo próprio ocupante).

- Ampliação ou enriquecimento do cargo (horizontal ou vertical). 
Assim como os fatores higiênicos:

\author{
Condições de trabalho e conforto pessoal; \\ Políticas da empresa e administração; \\ Relacionamento com o supervisor; \\ Competência técnica do supervisor; \\ Salários e benefícios sociais; \\ Segurança no Cargo; \\ Relacionamento com os colegas (CHIAVENATO, 2009, p.129)
}

Em Chiavenato (2009) há uma analogia entre as ideias de Maslow e Herzberg,onde este traz a motivação no ambiente de trabalho e aquele, através das necessidades humanas.

O enriquecimento das tarefas pode ser organizado da melhor maneira que convir a empresa e sempre que necessário. Importante desta teoria diz Macedô (2007) é que de nada adianta ter política higiênica se não houver valorização e reformulação no ambiente escolar.

\title{
2.3 LIDERANÇA
}

A liderança nos dias atuais está ligada a ideia de obter sucesso, ter poder de persuasão e de influência para que as pessoas através da motivação atinjam os objetivos traçados e sejam o quanto antes atingidos.

O bom líder encoraja, desenvolve e motiva os colegas de trabalho, pois somente através da motivação teremos funcionários comprometidos com o sucesso da organização.

Ser um referencial, ser admirado e respeitado são características primordiais do líder que as organizações buscam ter em seus quadros administrativos.

\footnotetext{
A liderança é um fenômeno tipicamente social que ocorre exclusivamente em grupos sociais. Podemos defini-la como uma influência interpessoal exercida numa dada situação e dirigida através do processo de comunicação humana para a consecução de um ou mais objetivos específicos. "[...] a liderança é um tipo de influenciação entre pessoas: [...] na qual uma pessoa age no sentido de provocar o comportamento de uma outra, de maneira intencional. (Chiavenato, 1994, p.147)
}

Segundo Bergamini (2008) o que se espera de um líder é que ele consiga fazer o grupo produzir perante os objetivos a serem alcançados, quando isto ocorre o grupo fica satisfeito, o líder é a pessoa que fica responsável pela moral e pelo bem estar do 
grupo. Ainda segundo o autor o líder está atento ao ajuste necessário e o desenvolvimento individual de cada indivíduo do grupo num contexto grupal.

\subsection{TIPOS DE LIDERANÇA}

A teoria mais referenciada e que vai ser usada neste trabalho para análise das respostas será a de White e Lippitt (1939). Fachada (2003) explica que há três estilos de liderança segundo estes autores: Autoritária, Liberal e Democrática.

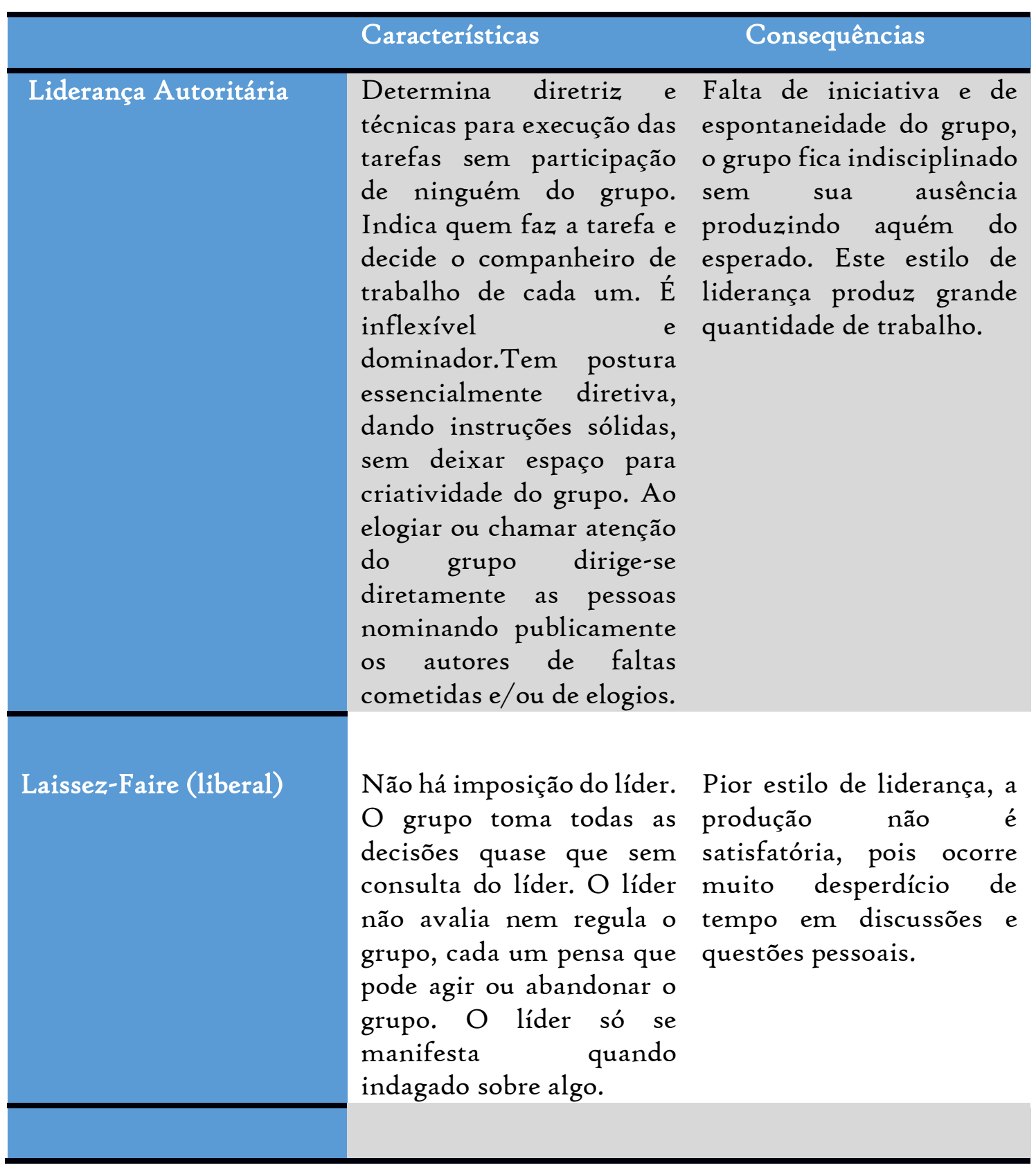


Líder Democrático

Lider Democrático
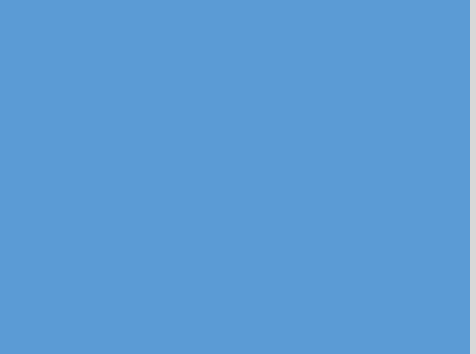

É um membro igual a todos no grupo, instiga o diálogo no grupo, torna todos participantes das decisões, o grupo decide as providências e técnicas a serem realizadas, quando tece um comentário limita-se ao fato ocorrido.

\author{
Ritmo de trabalho suave, \\ seguro e de qualidade, \\ mesmo na ausência do \\ líder. Ocorre orientação e \\ apoio do líder. É o estilo \\ que produz maior \\ qualidade de trabalho
}

Fonte: FACHADA, 2003. (adaptação do autor)

\section{3. DISCUSSÃO/ANÁLISES DOS RESULTADOS}

Ao escolher a escola particular de Educação Infantil do município de São Jerônimo a ideia motivacional deste trabalho era ver pelo olhar da gestora escolar como a própria vê a sua liderança perante os colegas e a comunidade escolar e como ela trabalha a motivação de seus funcionários.

A escola tem 120 alunos, trabalha das 7 h3omin às I7h3omin, de segunda a sextafeira. Possui 24 funcionários, dentre estas sete professoras, I4 monitoras, 2 auxiliares de limpeza e 2 cozinheiras. Servem 3 refeições diárias e muitos pais ainda solicitam o horário extra até as $19 h$, pois saem do serviço após as I8hzomin.

A diretora é formada em Pedagogia, tem pós em Gestão Escolar e está no cargo há pouco mais de dois anos.

Para o desenvolvimento deste trabalho foi feito cinco questões abertas para que a gestora respondesse com suas palavras sobre o assunto motivação e liderança.

Abaixo estão os dados coletados e a suas análises registradas: I a pergunta: "Você como gestora escolar encara quais dificuldades perante o cenário da educação no país?"

Gestora: Trabalhar com educação está bastante difícil, muitas vezes os pais e os próprios funcionários enxergam a escola infantil como uma recreação, sem precisar alcançar metas de desenvolvimento dos alunos e sem a necessidade de uma cobrança maior aos professores. Há pouco solicitamos inscrição no Estado e nos foi solicitado uma gama de documentos que quando assumi não existiam na escola ou estavam totalmente defasados, necessitando assim de uma nova repaginação adequando assim às necessidades da escola, dos alunos e dos funcionários. Nossas maiores dificuldades 
são a manutenção da escola, por ser particular e ser filantrópica o dinheiro arrecadado com as contribuições dos pais servem apenas para o pagamento dos funcionários, exigindo de todos nós esforços através de campanhas, rifas e pedágios para angariar outros valores para a manutenção do prédio e pequenas reformas. As escolas do município são gratuitas e muitos pais até transferem os filhos para lá, mas voltam, pois as crianças não se adequaram e as necessidades dos pais não são sanadas como nós buscamos fazer. É trabalhoso pensar na gestão, na direção e no pedagógico, muitas vezes nossos professores solicitam material pedagógico e não temos como obter, buscamos sempre que possível trazer ao nosso profissional o melhor que podemos oferecer pois temos a certeza que o trabalho realizado é muito bem feito, deixando a comunidade escolar e o grupo realizado e na busca do queremos mais.

$2^{2}$ - pergunta: Como você vê sua liderança perante o grupo? Que tipo de líder é você: autoritário, democrático e laissezfaire?

Gestora: Busco ser uma líder democrática, onde a equipe tem o direito de opinar e ajudar a buscar soluções para os problemas da escola. Gosto de fazer parte do grupo sem ter diferenciação, é somente um cargo que tem mais responsabilidades, mas não me faz diferente de ninguém, até porque como quem escolhe é a direção da casa formada pela presidente, vice, secretárias e tesoureiras, não é cargo eletivo, costumo dizer que estou diretora/gestora e não sou uma. Gosto e procuro ouvir opiniões de todos, de pais, da comunidade, dos colegas em geral, pois sempre enxergam com outro olhar as coisas e podem surpreender com as soluções. Acredito que muitas vezes precisamos ser incisivos em alguns assuntos, agindo autoritariamente, mas quando isso acontece e é raro, é para defender o bem da escola e de sua qualidade de ensino. $3^{-}$questão: Como trabalhar a motivação num grupo tão diverso? Quais fatores mais motivam os funcionários e quais os fatores que não estão motivando os funcionários em sua opinião?

Gestora: Aqui na escola buscamos conversar muito com o grande grupo, com pequenos grupos e individualmente, pois por trabalharmos com pessoas existe a necessidade dessa atenção aos que auxiliam no cotidiano escolar. Ao começarmos o ano realizamos, a presidente e eu uma reunião de boas vindas, um café da manhã para as colegas e ali começamos a desenhar o ano letivo, com sua programação mensal, 
deixando as colegas definirem as pequenas comissões que cuidarão de cada festividade. Não gosto da imposição, eu acredito que cada um participando de uma festividade que goste fica mais interessante a participação e as pessoas ficam motivadas a fazerem o melhor, deixando a equipe feliz. Depois desta reunião temos as pequenas reuniões, onde ouvimos cada setor, seus desejos e suas precisões, buscando contentar a todos mesmo dentro do apertado orçamento da escola, busco ouvir e argumentar opiniões e reclamações de todos, tentando dirimir tudo da maneira mais rápida e franca. O que mais motiva os funcionários da casa é justamente essa abertura de diálogo e o reconhecimento do trabalho realizado, sempre que acontece algo diferente, seja uma festividade quanto um teatro faço questão de parabenizar e reconhecer o esforço dos colegas, fotos dão divulgadas na internet através das redes sociais e o whatsapp dos pais sempre recebem essas criações das professoras. As respostas são quase que instantâneas, deixando o grande grupo muito feliz e disposto a criar mais coisas para a próxima festividade. Nem tudo são flores, por mais que busquemos a motivação constante, nem sempre há solução para tudo, a comunicação é algo que ainda fica a desejar, embora o grande grupo seja formado por excelentes profissionais, as informações distorcidas e repassadas adiante apresentam um problema sério que em diversos locais ocorrem. Busco resolver com muito diálogo, mostrando o quanto isso pode minar o relacionamento entre os colegas, fazendo com que muitos se desmotivem sem razão alguma, apenas porque alguém criou ou inventou tal informação, já diminuiu bastante esta situação, mas ainda tem incomodado bastante muitos do grupo. Outro fator que desmotiva o grupo é a pouca remuneração oferecida, já perdemos inúmeros profissionais maravilhosos porque obtiveram propostas salariais melhores. Buscamos dar um aumento aos nossos funcionários, mas infelizmente a inadimplência dos pais por inúmeros motivos não nos deixa fazer isso com a responsabilidade necessária para cobrir os gastos.

$4^{\underline{a}}$ questão: Como são resolvidos os impasses e as dificuldades durante o dia a dia escolar?

Gestora: Motivar a pessoa que passa por um problema ou trazer a motivação para um grupo com impasses de opiniões é primordial, pois se sentem acolhidas e fazendo parte da escola. Normalmente há briga de egos, uma quer aparecer mais que 
as colegas ou deseja mandar em tudo e as outras não podem dar opiniões, sim esses impasses acontecem, mesmo o grupo escolhendo com quem trabalhar. Motivações diferentes as fazem agirem assim, às vezes estão muito engajadas e querem expor ideias e ideias e aí é preciso fazer uma reunião com o grupo, ouvir todas e trazê-las para a realidade e buscar intermediar a melhor maneira de tudo acontecer como planejado sem frustrar ninguém. Muitas vezes temos nesses grupos meninas que fazem tudo sozinha, não gostam de delegar nada a ninguém por serem perfeccionistas, assim como temos algumas que se escoram no trabalho de outras, fugindo da criação e de ter maiores responsabilidades, a motivação precisa pegar o grupo senão a coisa não anda, quando a dificuldade se torna muito séria é necessário intervir de forma mais incisiva, chamando atenção para o descaso ou para a reclamação feita pelo grupo. Tudo se resolve a base de diálogo na escola, conversando e esclarecendo as coisas com o grande grupo quando possível e se não for assim, resolve-se na sala da direção diretamente com os envolvidos.

$5^{\underline{a}}$ pergunta: Como a gestão escolar vê a relação dos professores com os pais e demais pessoas da comunidade? Existe alguma motivação nesta relação?

Gestora: Nos primeiros meses de direção foi muito complicado fazer o grande grupo entender que a relação da escola com a família passava pela motivação deles perante o serviço, quando tínhamos algum galeto, sopão ou mesmo rifas não compravam e não faziam muita questão de chamar os pais e a comunidade pra tal atividade. Hoje já ocorre uma pequena mudança com muitos, mas ainda temos funcionários que não ajudam a escola neste sentido de angariar fundos, dão inúmeras desculpas e fogem de fazer sua parte. Em contra partida os pais estão motivados a conseguirem mais e mais contribuições e melhorias para a escola, trabalhamos com os pais da mesma maneira que com os funcionários, temos o grande grupo que participam das assembleias e votam nas demandas que a presidente põe em votação, há um pequeno grupo de pais que são os mais dão ideias e participam efetivamente do cotidiano escolar, estão sempre motivados a dar uma escola parceira e de boa qualidade para os filhos. Quando os pais se sentem prejudicados ou não satisfeitos com algo usamos o diálogo para entender e poder resolver os acontecidos, a busca pelo melhor está sempre ocorrendo, pois é para o bem da escola e da comunidade. 
Ao analisarmos as respostas, podemos ver que as motivações dos funcionários estão no topo da pirâmide de Maslow, a busca pelo reconhecimento e a autorrealização faz parte do cotidiano dos professores e demais profissionais da escola. A teoria de Herzberg se apresenta pelos fatores motivacionais da responsabilidade, da apresentação e demonstração de suas habilidades e competências, porém aparecem também os fatores higiênicos do salário e do relacionamento com os colegas que algumas vezes desmotivam uns e outros, mas após o diálogo todos voltam a buscar os mesmos objetivos. Na teoria de Douglas McGregor encontramos os fatores da motivação ser algo presente no cotidiano da escola e também a busca pelas responsabilidades e desafios, algo constante no cotidiano da escola e que todos fazem questão de estarem presentes, seja a escola em si como a comunidade.

A liderança da gestora mostra-se democrática, desenvolve todo o trabalho pedagógico e administrativo com os colegas, demonstra a realidade e busca com o grupo a solução para os problemas da escola, aceita opiniões e o diálogo é algo constante no seu cotidiano, todos na escola são importantes e a base da relação humana é a conversa e a troca de ideias.

\section{4. CONSIDERAÇÕES FINAIS}

Neste trabalho foi pesquisado como uma gestora via sua liderança e motivava seus colegas de trabalho no cotidiano de uma escola infantil em São Jerônimo/ RS. Através s das teorias motivacionais de Maslow, Herzberg e McGregor buscou-se caracterizar os aspectos motivacionais existentes nas respostas dadas ao questionário feito a gestora, assim como buscamos classificar seu estilo de liderança pela descrição feita a nós. Este trabalho foi enriquecedor pois muitas vezes ao vermos uma escola não sabemos o quanto de motivação de parceria precisa ocorrer para que o sucesso - aqui traduzido por educação de qualidade - ocorra. São muitas pessoas num mesmo local com o mesmo objetivo, porém com motivações diferentes e importantes.

Os objetivos traçados foram alcançados, o gestor é peça fundamental na escola, ele administra, dirige, motiva e lidera todo um grupo para fazerem um trabalho perfeito, sem a motivação e sem a liderança nada disso é possível, o gestor precisa ser 
líder para trazer os colegas juntos no sucesso, precisa motivar para mover os colegas da estagnação, gerir pessoas é uma arte que precisa de muita lapidação, aqui podemos traduzir por diálogo, coragem e desenvoltura. Trabalhar com pessoas é algo fascinante, poder motivar o outro para o crescimento profissional e pessoal é muito gratificante, ao realizar este trabalho percebemos que na escola há um grupo motivado e muito unido, com suas desavenças e discordâncias, mas nada que o bom diálogo e muita perseverança não de um jeito.

Uma sugestão para trabalhos futuros é que se faça essa mesma pesquisa com o grande grupo, pedir a eles que avaliem a gestora e o grupo da mesma forma que fizemos aqui, com certeza surgirão novos pontos de vista capazes de produzir novos diálogos e informações importantes.

\section{REFERÊNCIAS}

BERGAMINI, C. W. Motivação nas organizações. 5 ed. - São Paulo: Atlas, 2008.

CHIAVENATO, I. Gerenciando pessoas: o passo decisivo para a administração participativa. 2. ed. São Paulo: Makron Books, 1994.

CHIAVENATO, I. Administração de recursos humanos: fundamentos básicos. 7 . ed. São Paulo: Atlas, 2009.

CHIAVENATO. I. Gestão de Pessoas: o novo papel dos recursos humanos nas organizações. 4ed. Barueri. SP: Manole, 2oI4.

FACHADA, M. O. Psicologia das Relações Interpessoais. 6. Ed. Lisboa: Rumo. 2003 GIL, A. C. Gestão de pessoas: Enfoque nos papéis profissionais. I ed. - São Paulo, 2011.

LUCK, H. Concepções e processo democráticos de gestão educacional. 5. ed. Petrópolis: Vozes,2oro.

MACÊDO, I. I.; RODRIGUES, F. D.; PUPE E. M;CUNHA, M. M. N. Aspectos Comportamentais da Gestão de Pessoas. 9 ed.Rio de Janeiro - RJ: FGV, 2007.

MINICUCCI, A. Psicologia aplicada à administração. 5 ed. - São Paulo: Atlas, 2008.

PARO, V.H. Gestão Democrática da Escola Pública. 3ed. São Paulo: Ática, 2008. 
ROBBINS, S. P. Fundamentos do Comportamento Organizacional. - São Paulo: Pearson Education do Brasil, 2014.

VELERIEN, J., DIAS, J.A. Gestão da Escola Fundamental: Subsídios para Análise e Sugestão de Aperfeiçoamento. São Paulo: Cortez; Brasília: Unesco/Mec, 1992. 